\title{
Recommendations of the Group of Experts of the Polish Society of Gynecologists and Obstetricians in the field of gynecological and obstetric care of young women with physical and intellectual disabilities
}

\author{
Agnieszka Drosdzol-Cop ${ }^{1}{ }^{1}$, Anna Fuchs $^{1}{ }^{\mathbb{D}}$, Violetta Skrzypulec-Plinta ${ }^{2}$, \\ Dariusz Radomski ${ }^{3}$, Grazyna Jarzabek-Bielecka ${ }^{4}$, Iwona Czech ${ }^{1}{ }^{\circledR}$, \\ Agnieszka Dulska' ${ }^{1}$, Mateusz Szul' ${ }^{1}$ (D) \\ ${ }^{1}$ Department of Pregnancy Pathology, Department of Woman's Health, School of Health Sciences in Katowice, \\ Medical University of Silesia, Katowice, Poland \\ ${ }^{2}$ Department of Woman's Health, School of Health Sciences in Katowice, Medical University of Silesia, Katowice, Poland \\ ${ }^{3}$ Raddar-Med, Warsaw, Poland \\ ${ }^{4}$ Division of Developmental Gynecology and Sexology, Department of Perinatology and Gynecology, \\ Poznan University of Medical Sciences, Poland
}

\begin{abstract}
The recommendations present the current knowledge and procedures, which can be modified and changed in some cases, after careful analysis of a given clinical situation, which in the future may become the basis for their modification and
\end{abstract} updating.

In pediatric gynecology each medical action should be adjusted to patient's age, stage of her physical and mental development, and in case of a disable patient, the type of her disability should be individually taken into consideration.

A person with a disability is defined as a person with a physical or mental impairment that substantially limits one or more major life activities. Mental or physical disability is a crucial factor that impedes the implementation of gynecological and obstetric standards of care, especially in pediatric group of patients. Pediatric gynecologists must not only be characterized by multidisciplinary knowledge but also be able to build good interpersonal relations with young patients.

Women and girls with disabilities have rights to obtain gynecological and obstetric care.

The health awareness of women in Poland is low, and what's more the awareness of women with disabilities is even lower. The necessary element to broaden their knowledge and awareness is to provide each woman with disabilities an easy access to specialists and medical care. In addition, it is important to provide girls with visual impairment a non-stressful and intimate atmosphere during the gynecological visit and physical examination. The second crucial element is to enable women with disabilities to gain reliable and easy-provided medical knowledge, thus these women are often disinformed because of their lower educational status in comparison to general population.

Many findings and observations show, that Polish society is very traditional in terms of many negative stereotypes that are absent in other countries of the European Union. These stereotypes include also an opinion that a person with disability doesn't have sexual needs. Because of that, disabled people are often marginalized in terms of sexual, gynecological and obstetric care. Meanwhile, the World Health Organization emphasizes, that sexual activity in people with disabilities is one of the most one of the most neglected fields and requires the cooperation of specialists from various fields [1].

\section{MEDICAL HISTORY OF A PATIENT WITH DISABILITIES}

The strategy of interviewing disabled patients must be individually adapter depending on the type of the disability. The anamnesis of a patient with physical or mental disability differs significantly from interviewing a patient without any disabilities. Medical healthcare providers may not have 
difficulties in interviewing women with isolated physical disabilities, however they have to take into consideration potential information about sensory disturbances due to paralysis or ischemia of some parts of the body.

When discussing the clinical impact of disabilities on women's reproductive health, it's important to remember that these women have the full right to procreation. Providing optimal conditions for conducting pregnancy of a disabled woman, as well as choosing between the natural birth and the cesarean section, requires consideration of specific neurological and orthopedic conditions [2]. The authors' own experiences show, that physicians often do not ask the patients about the presence of genital ailments which maybe a result of the disability. Patients with spinal cord injury often experience oligomenorrhea or amenorrhoea within 12 months after the injury. In this group of women, genital sensory disorders are also common and may negatively affect their sexual activity. Therefore, collecting reliable gynecological history from a disabled woman requires interdisciplinary medical knowledge. During the interview, the patient's specific mental state should be also taken into account, which may be the result of an accident trauma.

Interviewing the physically disabled person does not seem to differ significantly from the standard method of collecting medical records. However, you cannot forget that in some cases, a change in collecting the medical history may be necessary. For example, a girl with cerebral palsy may have impaired speech, so that she may not be understood by the doctor. In that cases, the girls' guardians may play a role of a "translator", while special care should be taken so that he does not create a virtual clinical picture of the patient. Another idea is to prepare a standardized model of collecting medical records from disabled patients.

Speech or hearing dysfunction are another important type of physical disability. The most necessary thing in this situation is the involvement of a professional sign language interpreter. However, this is not possible in the emergency cases and the doctor must deal with the situation. One of the most common mistakes doctors make, is to try to have a written conversation. Unfortunately, this is often a completely ineffective method. Of course, secondary deaf people - after accidents or operations have the ability to read. Unfortunately, deaf people from birth use a much poorer word resource. If we use this method of communication, use simple messages. Simple messages also apply to speech - many patients are great at reading lips. In this situation, we use simple sentences and turn to the patient so that she has the chance to read as much as possible from our lips.

In the contact with a deaf patient, the previously developed gynecological interview questionnaire can be used. In addition, standardized communication cards, such as the one presented in Supplementary Annex 1 (see journal website) [3] are worth to be used. Their guardians can help us in an interview with a deaf person. As long as the guardian is an adult, we use all previously known methods of collecting anamnesis. A communication problem occurs when the interpreter is a child. CODA (Children of Deaf Adults), i.e. deaf adults, often accompany deaf parents or siblings in a doctor's office. The conversation mediated by the child is extremely difficult but sometimes it is the only way to contact the patient. Then, any difficult term should be thoroughly explained to the child, bearing in mind that his vocabulary may be severely limited (through constant contact with deaf people and age) so that it can be passed on to the parent as much as possible [4]. Of course, doctors using sign language will find it much easier to communicate with a deaf patient. Despite this, it should be borne in mind that in contact with such patients we use total communication - speech, gestures, drawings, notes. Only in this case the patient has the best chance of understanding the doctor correctly.

Another difficult challenge concerns interviewing a blind person. During the conversation we should remember that she lost a lot of information, i.e. on the observation of the intensity of menstrual bleeding.

Subject examination of a patient with intellectual disability depends on its level. People with severe disabilities often communicate in simple, two-word sentences or non-verbally (gestures, facial expressions with vocalization). Speech disorders often significantly distort the statement, which makes it incomprehensible to the environment and often causes the disabled person's unwillingness to communicate. Difficulties also apply to the reception of information, so when talking to an intellectually disabled person, avoid statements that are too complex and contain abstract concepts. Often, disabled patients have disturbances in the functioning of their senses, which is manifested by a delayed reaction or sometimes an inadequate response to a stimulus, e.g. in the form of hypersensitivity.

People with severe intellectual disability (IQ below 20) usually communicate non-verbally, using gestures such as pointing, handing objects, leading by the hand towards the desired object. Their health situation causes total dependence on caregivers. In these people, physiological functions such as breathing, sucking, chewing, biting, swallowing and phonation are very disturbed. People with deep disabilities often have many of severe neurological defects, physical defects impairing mobility, epilepsy, and sensory damage. They require specialist health and rehabilitation care to prevent the occurrence of acute recurrent infections [5].

It should be remembered that disabled girls, as particularly vulnerable victims, and they are more likely to experience sexual offenses. The problem of sexually abused children is a special problem of pediatric gynecology, and even more difficult for disabled girls. 


\section{PHYSICAL EXAMINATION (PE) OF DISABLED PATIENTS}

Even the preparation for the physical examination is important. Even such a simple act as undressing is often difficult for disabled patients. This creates psychological discomfort for them, and raises technical problems, which is why you need the help of a caregiver, paramedic, nurse or midwife who works with a doctor.

Gynecological examination concerns the most intimate spheres and problems in a woman's life. Incorrectly conducted, it can cause shame and stress in some patients. This particularly applies to the first gynecological examination in life, because it can affect the behavior of a girl or woman in subsequent stages of gynecological diagnostics, and it may affect her psychosexual development. It is very important for disabled patients to maintain particular intimacy during the examination and to create the right atmosphere of respect for girls' shame and trust. In little girls, cooperation with the mother is necessary. When collecting the interview, the mother may pay attention to the details of the daughter's disability, conditions and her development, which are important for the diagnosis. In addition, the presence of the mother during a gynecological examination can give the child a sense of security

A really important clinical problem is the way the gynecological examination is performed. The main difficulty reported by the patients during gynecological examination is taking appropriate position on the gynecological chair. This is often associated with the technique of moving from a wheelchair to a higher gynecological chair. In addition, in girls and women with spastic paralysis, a big problem is the position of the lower limbs on the footrests or the relaxation of the perineum muscles enabling the examination. The solution to these limitations is to carry out the examination on a couch or wheelchair in positions known in general gynecology and girls' gynecology. In addition, some authors are also considering the possibility of examining disabled patients under anesthesia.
When preparing do perform a gynecological examination of a disabled patient, it should be taken into account that examination of such a patient may require much more time. In addition, it is worth remembering that in the case of patients with cerebral palsy, as well as in some with trauma of the nerve core, the relaxation time is significantly longer. If such examination was not possible to perform, the method of choice is only abdominal ultrasound control.

After the gynecological examination, the physician should record in the documentation the results of the examination, taking into account the patient's age, type of disability, stage of physical development according to the Tanner scale, clitoral size, type of hymen, hygienic condition, type of uterus, data from the gynecological and ultrasound examination of internal genital organs and laboratory tests results.

\section{OBSTETRIC CARE OF A YOUNG PATIENT WITH DISABILITIES}

The term "juvenile pregnant mothers" or "teenage mothers" refers to young girls who become pregnant and / or have given birth before the age of 18 [6]. According to WHO, every year, 16 million teenagers between 15 and 19 years old become mothers, and teenage pregnancies primarily affect less educated girls from poorer backgrounds. The pregnancy of adolescent women is not only a medical problem, but also a social and psychological one, and if it concerns an adolescent physically or mentally disabled it is an even more important problem. Women with disabilities are more likely to be victims of physical and psychological violence, sexual abuse, and they are exposed to unstable living conditions, low social status, poor diet and a sedentary lifestyle [7]. An adolescent's pregnancy is usually unplanned and given the fact that disabled girls, as particularly vulnerable victims, and are more likely to undergo sexual offenses, pregnancy may be the result of such violence [8]

Pregnancy in teenage disabled woman still occurs relatively rarely, which makes it difficult to thoroughly analyze the impact of factors directly related to a given disability

\begin{tabular}{|c|c|c|}
\hline Position & Characteristics & Reccomendation \\
\hline „Side-knee” position & $\begin{array}{l}\text { The patient is lying on the couch on her side. The lower outer limb bent with the knee pulled } \\
\text { to the chest and raised by the midwife. The lower inner limb remains visited backwards. This } \\
\text { position allows limited palpation, in particular the back wall and posterior vaginal arch are } \\
\text { available. }\end{array}$ & $\begin{array}{l}\text { Recommended in situations } \\
\text { with severe spasticity }\end{array}$ \\
\hline $\begin{array}{l}\text { „Diamond/rhombus” } \\
\text { position }\end{array}$ & $\begin{array}{l}\text { The patient lies on her back, the feet are joined together, the lower limbs bent at the knee } \\
\text { joints, maximally deflected (the outer side of the knee joints rests on the couch). Limbs bent } \\
\text { at hip and knee joints form a diamond shape. }\end{array}$ & $\begin{array}{l}\text { Recommended for patients } \\
\text { with limited mobility in the } \\
\text { hip joint }\end{array}$ \\
\hline "M" position & $\begin{array}{l}\text { The patient lies on the couch, the lower limbs bent at the knees rest with her feet on the couch. } \\
\text { After abducting the limbs forming the letter " } \mathrm{M} \text { ", the position is similar to the classical } \\
\text { position of the gynecological examination. }\end{array}$ & $\begin{array}{l}\text { Recommended for pediatric } \\
\text { patients }\end{array}$ \\
\hline${ }_{\text {}} \mathrm{V}$ " position & The patient lies on her back, the limbs are straightened and extended. & $\begin{array}{l}\text { Recommended when PE is } \\
\text { performed on a wheelchair }\end{array}$ \\
\hline
\end{tabular}


on pregnancy, delivery and the health of the fetus and newborn baby. This provides many difficulties and doubts in perinatal care in this group of patients. According to the literature, pregnant women with physical or intellectual disabilities are more often exposed to such complications during pregnancy and delivery as preeclampsia, small growth gestational age (SGA), preterm delivery, higher perinatal mortality, and venous thrombosis [7]. Casuistic experiences with cooperation with disabled women also confirm the frequent anxiety of obstetricians before undertaking the pregnancy of a disabled patient.

The data available in the the literature clearly show that the pregnancy of a patient with physical disability should always be treated as a high-risk pregnancy. In the care of a pregnant woman with a disability, special attention should be paid to [9]:

- greater risk of falling due to disability and weight gain during pregnancy;

- cardiovascular and respiratory disorders occurring during pregnancy, which are further compounded by disability;

- nutritional problems.

The delivery of a disabled woman should be carried out with respect for her rights to make informed decisions regarding the delivery process, choice of delivery site and the person caring during delivery [10].

Most frequently, the factors complicating the course of pregnancy, delivery and puerperium result from the neurological and orthopedic condition of the disabled patient and are specific to the disease which is the primary cause of physical disability. Therefore, the proposed recommendations will be limited to two groups of women with disabilities: patients with spinal cord injuries and patients with multiple sclerosis (MS). From epidemiological data and the authors' own experience, it appears that these are the dominant causes of physical disability of women at the age of greatest reproductive potential.

Obstetric care of a pregnant woman with physical disabilities must be carried out by a multi-specialist team made up of the following specialists: an experienced obstetrician, neurologist, physiotherapist. Constant cooperation should be maintained with the internist who has knowledge of the internist problems of a disabled pregnant woman.

\section{Patients after spinal cord injury}

Patients after spinal cord injury are not affected by reduced fertility. Both the level of spinal damage and the degree of damage do not affect the woman's monthly cycle. Shortly after spinal cord injury, amenorrhea occurs, however menstruation returns approximately six months after damage. Patients with spinal cord injury may have severe menstrual and premenstrual discomfort [11-13].
The factors influencing the course of pregnancy in a group of patients with spinal cord injury are:

a) Increased incidence of lower urinary tract infections and worsening of neurogenic bladder symptoms that are a direct threat to preterm birth.

b) Reduction of vital capacity of the lungs, problems with proper breathing, impairment of respiratory muscle efficiency. This can lead to more frequent hypoxia and compensatory tachypnoe and tachycardia.

c) Impaired intestinal motility and absorption, leading to frequent constipation and an increased risk of anemia.

d) Circulatory disorders as well as inactivity of the lower limbs greatly increase the risk of venous thromboembolism.

e) Weight gain and a change in its distribution leads to more frequent pressure ulcers, mainly around the sacrum.

f) Occurrence of autonomic dysreflexia in patients with spinal cord injury at Th6 level or above during obstetric examination or delivery. This phenomenon is based on increased autonomic reflexes suggesting the onset of preeclampsia. There is an increase in blood pressure, bradycardia, headache, sweating, edema, induction or intensification of uterine contractions including tetanus contractions. There is also vasoconstriction in the uteroplacental circulation leading to fetal hypoxia.

g) The reduction of deep sensation in patients with spinal injury located above the Th 12 vertebra makes it difficult for the patient to feel the fetal movements and contractions predicting delivery.

Little is known about the lactation in women after spinal cord injury. Damage to the spinal core at Th6 or higher may result in shorter lactation time and a reduction in the amount of milk. Patients at risk must also know that irritation of the nipples during feeding may experience autonomic dysreflexia. It is recommended that this group of patients use the assistance of lactation advisers [14].

\section{Patients with multiple sclerosis (MS)}

MS is most often diagnosed at the age of $20-40$, that is at childbearing age. For this reason, the effect of pregnancy on MS is a clinically relevant issue. Patients with MS are not less fertile than healthy women, and no negative impact of MS on pregnancy or delivery has been demonstrated. Pregnancy significantly reduces the risk of MS relapse (especially during the third trimester of pregnancy) [15]. It is recommended to discontinue immunomodulatory therapy during pregnancy and feeding the newborn, and some disease-modifying drugs should be discontinued several months before the planned pregnancy [15]. The risk of recurrence of disease increases 6 months after delivery, so it is recommended that the patient returns to preventative treatment as soon as possible by using immunomodulatory drugs. 


\section{CONTRACEPTION IN ADOLESCENTS WITH PHYSICAL OR INTELLECTUAL DISABILITIES}

The right to independently plan your own partner life and decide on the number of offspring and the frequency of pregnancies is one of the components conditioning reproductive health. This right only applies if everyone has equal access to a variety of contraceptive methods. The results of world studies and a few Polish works indicate that people with physical or mental disabilities significantly less often use modern methods of contraception.

The wide range of contraceptive methods available in terms of their effectiveness, comfort of use and contraindications has given rise to the need to develop PTGiP recommendations regarding methods of pregnancy prevention, with particular emphasis on hormonal contraception.

All recommendations published so far undoubtedly apply when choosing the contraceptive for a disabled patient. However, specific health conditions that directly result from the nature of disability may constitute additional indications or contraindications for a given method of contraception.

\section{RECOMMENDATIONS FOR PATIENTS WITH PHYSICAL DISABILITIES}

According to epidemiological data, the most common causes of physical disability in people of reproductive age are spinal cord injuries, cerebral palsy, and multiple sclerosis. Therefore, the proposed recommendations for patients with physical disabilities were formulated with particular regard to the above-mentioned causes of physical disability.

1. Physically disabled women, depending on severity of the mentioned disability, should adjust both her sexual life and optimal method of contraception, previously seek for sexuological consultation if needed

2. Physical disability often leads to emotional and caring dependence on caregivers. If the presence of a disabled person's guardian is not necessary, the method of contraception should be chosen without the presence of accompanying persons.

3. Regardless of the degree and etiology of physical disability, the choice of contraception method must be preceded by: an interview taking into account information on the cause of the disability and a standard physical examination, also taking into account the severity of motor dysfunction hindering the use of the contraceptive method.

4. The possibility of self-use of the contraceptive method by a patient with physical disabilities should be an important criterion for her choice.

5. An equally important condition for choosing a method should be the frequency of sexual intercourse, which can be much lower when compared to the general population.

6. The use of barrier contraceptives should not be recommended for patients with significant grade of spastic paresis due to difficulties in putting the vaginal ring or condom on properly.

7. The use of low-dose oral hormonal contraceptives is recommended for women with severe physical disabilities, unless otherwise indicated.

8. The transdermal hormonal contraception may cause discomfort to a patient during care treatments performed by the caregiver. An alternative method is to propose a hormonal contraceptive in the form of Depo-Provera.

9. The choice of hormonal contraception method must take into account the patient's level of motor activity. In patients moving on a wheelchair with paraparesi, the use of substances increasing the risk of deep vein thrombosis should be avoided. Monitoring of blood coagulation parameters is also recommended in this patient group.

10. Severe physical disability and the altered sensation in the urogenital area is an absolute contraindication to the use of IUD.

\section{RECOMMENDATIONS FOR PATIENTS WITH INTELLECTUAL DISABILITIES}

1. In choosing the appropriate method of contraception for patients with intellectual disabilities, it is important to first determine the degree of mental retardation. The ICD-10 and DSM V classification distinguish four main levels of intellectual disability $[16,17]$ :
a) mild intellectual disability
b) moderate intellectual disability
c) severe intellectual disability
d) profound intellectual disability

2. For patients with physical disabilities, the choice of contraceptive method is largely based on the risk of Venous Thromboembolism. Although it is also important for patients with mental retardation, the most important factor affecting the effectiveness of the selected contraceptive method is the possibility of its correct use by the patient and her caregiver. When choosing the right contraceptive method, the Polish Society of Gynecologists and Obstetricians recommends using the following criteria:

a) The results of previous studies indicate that people with intellectual disabilities, regardless of disability level, experience the sexual attraction and show desire to satisfy it.

b) The individual disability level is an additional criterion for choosing the appropriate contraceptive, for given patient. Women with moderate disabilities are usually aware of the risk of unwanted pregnancy, although they cannot consciously manage their own fertility. Women with profound disabilities meet their sexual needs at the level of unconditional reflex. 
c) In case of a patient with intellectual disability, the person taking care of the patient should also participate in choosing the method of contraception.

d) To ensure adequate health protection, the choice of contraceptive method must be preceded by a standard anamnesis and physical examination. An interview for aggravating risk factors should be collected from the patient caregiver. The physical examination should be expanded to include elements of general examination (e.g. visual evaluation of the vessels of the lower limbs) due to the inability to obtain sufficient information about the patient's medical condition without the medical records. Gynecological examination should also include an assessment of the potential symptoms of sexual abuse.

e) In case of patients with severe intellectual disability, the recommendation to use contraception may be given by the doctor, even if the caregiver does not report such a need. Prevention of unwanted pregnancies in this population is an important aim of gynecological care.

f) For patients with mild or moderate impairment, with well-cooperating caregivers, the use of oral hormonal contraception is recommended. The medicine must be selected individually for the patient so as to minimize the risk of undesirable bleeding, which worsens the maintenance of proper hygiene.

g) In the group of patients with severe intellectual disability it is recommended to use long-acting hormonal contraception.

h) For patients with intellectual disabilities, the use of transdermal contraception is not recommended due to the inability to constantly monitor the patch. However, this method is recommended for patients with physical disabilities.

i) The use of contraception in the form of IUD is recommended by some world experts. The authors of these proposals are less optimistic about patients with intellectual disabilities due to the limited control of potential adverse events associated with the use of IUD by the patient herself.

j) The effectiveness of barrier contraception in patients with intellectual disabilities is significantly lower than the known Pearl Index estimates. Therefore, their use is not recommended in this group of women.

\section{POSSIBILITIES OF BIRTH CONTROL IN PATIENTS WITH PHYSICAL AND MENTAL DISABILITIES}

People with physical and mental disabilities have the same right to information and assistance in choosing contraception methods as non-disabled people. PTGiP is of the opinion that modern contraception is the only effective way to prevent the unwanted pregnancies and their termination. That is why the education of the society regarding ways of family planning is so important in Poland. One of the most effective ways of birth control are hormonal contraceptives. There are several possible ways of hormone supply, among them:

1. Oral contraceptives

2. Transdermal hormonal contraceptive system

3. Contraceptive vaginal ring

4. Depot Medroxyprogesterone Acetate (DMPA) injections

5. Hormone-releasing intrauterine device (IUD)

Nowadays, thanks to the above-mentioned methods of contraception, it is possible to choose the appropriate method of administering hormones, individually to the patient, so as to minimize the risk of hormone therapy complications. However, it should be remembered that no hormonal drug is indifferent to one's health.

\section{ORAL CONTRACEPTIVES}

The use of oral contraceptives is one of the most effective methods of birth control, characterized by a low Pearl index and a relatively low risk of complications during use.

For many women with disabilities, monthly bleeding is extremely troublesome and often embarrassing. During this time, they require more frequent help in sanitary procedure while menstrual pains only further reduce the patient's comfort.

For this reason, the patient may be offered hormonal contraception in the form of pills taken continuously, without a seven-day break for menstrual bleeding [18]. However, complete amenorrhea is difficult to obtain and is reported only in $62 \%$ of patients. Planning withdrawal bleeding every 3 to 4 months may be a more effective method to reduce patient discomfort [19].

Among the main side effects of oral hormonal contraception are: increased thromboembolic risk and increased risk of progression of estrogen-dependent cancers, e.g. breast cancer. For this reason, women with a tendency to blood clot formation, with liver failure, elevated cholesterol, diagnosed with estrogen-dependent cancers and reported as smokers are advised against taking hormonal contraceptives $[20,21]$.

The immaturity of the hypothalamic-pituitary-ovarian axis in adolescents means that hormonal contraception for patients in this age group should be individually considered by a gynecologist. Low-dose contraception is recommended because of its reduced risk of venous thromboembolism (VTE), which is particularly important for physically disabled patients.

Low-dose contraception has a reduced risk of thromboembolism, which is due to the low dose of ethinylestradiol. 
These medicine significantly reduce blood coagulability, further reducing fibrinolysis, maintaining the concentration of fibrinolysis for coagulation at the appropriate level. Furthermore, oral estrogens increase HDL cholesterol and lower LDL cholesterol. These properties mean that low-dose contraception is recommended for physically disabled patients. [18].

Girls with disabilities have a higher risk of thromboembolic disease, hence the selection of the contraceptive method should be preceded by tests of coagulation parameters. In people with disabilities, special attention should also be paid to the composition of the hormonal drug and the method of its administration. Low-dose oral contraceptives with third generation progestagens are safer for people with disabilities [22].

\section{TRANSDERMAL HORMONAL CONTRACEPTIVE SYSTEM}

Another recognized method of contraception recommended for people with disabilities is hormonal contraception used as a patch (transdermal patch). The contraceptive patch may be the right solution for patients who have difficulty swallowing tablets. What's more, just like birth control pills, it can be glued continuously, without every three weeks of breaks with planned withdrawal bleeding after about 3-4 months of continuous use [23].

The transdermal patch is considered one of the most effective methods of contraception in adolescents. This method reduces the risk of skipping the daily dose of the hormone, and allows to maintain a constant concentration of hormones in the patient's body. Studies show that the main reason for the ineffectiveness of oral contraception is forgetting to regularly take birth control pills [24, 25].

There are no studies that directly address the topic of missed dose when using oral contraception by people with disabilities, although the use of the patch significantly minimizes this risk. The use of transdermal patches requires the attention of the patient or caregiver only once a week, not every day, as is the case of oral contraception.

To avoid possible skin irritation, it is not recommended to stick the patches in the same place for too long. This is especially important in the aspect of skin care for people with disabilities.

Some patients with intellectual disabilities may try to remove the patch, which makes it helpful to place it high on the back or buttocks. However, experts do not recommend the transdermal patch to patients with this type of disability due to the inability to constantly monitor the patch. Notwithstanding, this method is considered extremely beneficial for patients with physical disabilities.

An important advantage of the contraceptive patch is the fact that it does not force changes in a woman's lifestyle and does not hinder rehabilitation. The transdermal patch adheres perfectly to the body and is highly resistant to peeling. This is undoubtedly an advantage for people with disabilities who use a bath, a swimming pool or exercise during rehabilitation.

No less important, however, is the increased risk of blood clots and related complications arising from the use of transdermal patches. The use of patches is associated with a higher concentration of estrogens in the female body than when using oral contraceptives. Considering the above, the use of contraceptive patches is not recommended in people with a disability predisposing to thromboembolism [22].

\section{CONTRACEPTIVE VAGINAL RING}

Specialists recommend vaginal rings for all women of childbearing potential, especially those who have a high risk of unplanned pregnancy. This is an excellent method for women who are not disciplined in the daily use of birth control pills or the exposure of transdermal patch is not acceptable to them.

Potentially, contraceptive vaginal ring can be used for women and girls with disabilities who have difficulty taking oral medications or using another method of contraception. Of course, the same as with oral contraceptives and transdermal patches, the ring can be used continuously in exactly the same way as described above [26].

A non-disabled woman places the ring in the vagina by herself on the first day of the cycle and after 3 weeks she also removes it herself. Depending on the limitations of the patient's disability, the ring may be inserted by a caregiver.

However, the use of the ring in disabled adolescents raises some concerns. Self-assembly of the disc requires an appropriate level of agility, which is not always possible to achieve by people with physical disabilities. Moreover, the application method may be unclear for people with intellectual disabilities. The ring insertion performed by the caregiver seriously affects the sense of privacy of the disabled person. All of the above drawbacks have severely limited the use of this method of contraception in the population of people with disabilities [22].

\section{DEPOT MEDROXYPROGESTERONE ACETATE (DMPA) INJECTIONS}

Recently, the use of DMPA injections as birth control method in patients with intellectual disabilities is increasingly recommended.

This method involves the intramuscular administration of medroxyprogesterone acetate once every 3 months. This form of contraception is especially recommended for patients with severe mental retardation. These patients are at risk of incorrect use of other forms of contraception, misunderstanding medical prescriptions or skipping subsequent doses of oral contraception. 
What is more, DMPA is not only a contraceptive, but also suppresses menstrual bleeding. Amenorrhea in almost $60 \%$ of patients occurs after 1 year of using DMPA, and in nearly $80 \%$ after 5 years [27].

This method seems to be an extremely beneficial alternative for physically disabled patients who require daily care by a caregiver. The site of hormone injection is invisible to the caregiver, does not interfere during care procedures, and does not require more attention, as is the case with transdermal systems or oral contraception. There are, however, two significant problems in using this form of contraception for physically disabled adolescents.

First, the use of this medicine is associated with weight gain. This problem is troublesome for all teenagers, however, for teenagers with mobility problems, even a slight weight gain can complicate movement and thus reduce their independence [28].

Secondly, the topic of the impact of DMPA on bone mineral density (BMD) is increasingly discussed. The US Food and Drug Administration (FDA) recommends limiting the use of DMPA to a maximum of 2 years. This is especially important for teenagers because girls accumulate about $30 \%$ to $40 \%$ of their bone mass during puberty. The rate of BMD loss decreases with longer duration of DMPA use. The World Health Organization, ACOG, and Society for Adolescent Health and Medicine advise physicians to individually interpret the recommended 2-year period of use and discuss with the patient and her family the potential risks and benefits of this therapy [29].

In adolescents with disabilities and reduced mobility, bone mineral density may be reduced at the outset, but it is not clear whether this is associated with an increased risk of fractures. Loss of bone density appears reversible upon discontinuation of DMPA in women with disabilities, but there are no data on adolescents with reduced mobility [22].

\section{HORMONE-RELEASING INTRAUTERINE DEVICE (IUD)}

Intrauterine devices have been very readily used in adult women for many years, but it has only recently been recommended to use them in teenagers. The intrauterine device contains $20 \mu \mathrm{g}$ of levonorgestrel, of which $50 \%$ is consumed after about 5 years.

IUD has excellent contraceptive effects with a relatively small number of side effects. Due to the lack of estrogen component, it is not associated with such complications as e.g. venous thromboembolism. For the same reason, it is recommended for women with disabilities, especially in the case of intellectual disability. The described method also applies to women with physical disabilities associated with immobilization, which are excluded from the use of estrogen [30]. However, it should be borne in mind that significant motor disability, especially with the abolition of sensation in the urogenital area, is an absolute contraindication to the use of IUD.

The intrauterine device is especially recommended for people with intellectual disabilities. It is inaccessible to the patient and thus cannot be removed by herself.

Checking the correct placement of the insert in the gynecological office is extremely simple - ultrasound should be quite sufficient to assess the location of the inserted IUD. This is important in the case of patients who poorly tolerate gynecological examinations [22].

\section{REFERENCES}

1. Lew-Starowicz M, Długołęcka A. Seks trzyma nas przy życiu! Rehabilitacja seksualna w chorobach somatycznych. Leo Media, Warszawa 2015.

2. Xie E, Gemmill M. Exploring the prenatal experience of women with intellectual and developmental disabilities: In a southeastern Ontario family health team. Can Fam Physician. 2018; 64(Suppl 2): S70-S75, indexed in Pubmed: 29650748.

3. https://www.mp.pl/pacjent/pierwsza_pomoc/218757,kiedy-pacjent-n ie-slyszy?fbclid=IwAR3LcFT4oOjQjGk19VnZ iQfuLH3s66cr9Bmg6QrZAVJVJytLUqkQ6XIPxs.

4. http://www.codapolska.org.

5. https://www.pfron.org.pl/fileadmin/files/p/2393_P_D_P__Wsparcie_osob_z_uposledzeniem_umyslowym.pdf.

6. Marianowski L, Grzechocińska B. Prowadzenie ciąży, oraz poród i połóg u nieletnich. Medipress Ginekologia. 1996; 2: 2-5.

7. Brown HK, Kirkham YA, Lunsky Y, et al. Maternal and offspring outcomes in women with intellectual and developmental disabilities: a population-based cohort study. BJOG. 2017; 124(5): 757-765, doi: 10.1111/1471-0528.14120, indexed in Pubmed: 27222439.

8. Brown H, Kirkham Y, Cobigo V, et al. Labour and delivery interventions in women with intellectual and developmental disabilities: a population-based cohort study. J Epidemiol Community Health. 2015; 70(3): 238-244, doi: 10.1136/jech-2015-206426.

9. Sulima $M$, Lewicka $M$, Wdowiak $A$, et al. Opieka położniczoginekologiczna nad kobietami niepełnosprawnymi. European Journal of Medical Technologies. 2015; 4(9): 25-31.

10. Rozporządzenie Ministra Zdrowia z dnia 20 września 2012 r. w sprawie standardów postępowania medycznego przy udzielaniu świadczeń zdrowotnych z zakresu opieki okołoporodowej sprawowanej nad kobietą w okresie fizjologicznej ciąży, fizjologicznego porodu, połogu oraz opieki nad noworodkiem (Dz. U. Nr 112, poz. 654, z późn. zm.).

11. Stoffel JT, Aa FV, Wittmann D, et al. Fertility and sexuality in the spinal cord injury patient. World Journal of Urology. 2018; 36(10): 1577-1585, doi: 10.1007/s00345-018-2347-y.

12. Pannek J, Bertschy S. Mission impossible? Urological management of patients with spinal cord injury during pregnancy: a systematic review. Spinal Cord. 2011; 49(10): 1028-1032, doi: 10.1038/sc.2011.66, indexed in Pubmed: 21670736.

13. http://antybiotyki.edu.pl/wp-content/uploads/Rekomendacje/uklmoczowyinternet.pdf.

14. Holmgren $\mathrm{T}$, Lee AHX, Hocaloski $\mathrm{S}$, et al. The Influence of Spinal Cord Injury on Breastfeeding Ability and Behavior. J Hum Lact. 2018; 34(3): 556-565, doi: 10.1177/0890334418774014, indexed in Pubmed: 29787691.

15. Voskuhl R, Momtazee C. Pregnancy: Effect on Multiple Sclerosis, Treatment Considerations, and Breastfeeding. Neurotherapeutics. 2017; 14(4): 974-984, doi: 10.1007/s13311-017-0562-7.

16. Pużyński S, Wciórka J. Klasyfikacja zaburzeń psychicznych i zaburzeń zachowania w ICD-10. Opisy kliniczne i wskazówki diagnostyczne. Vesalius, Kraków 2000: 189.

17. Diagnostic and Statistical Manual of Mental Disorders DSM- $5^{\oplus}$, fifth edition Copyright $\odot 2013$ American Psychiatric Association.

18. NICE Clinical Guidelines, No. 30., National Collaborating Centre for Women's and Children's Health (UK). RCOG Press, London 2005.

19. Hee L, Kettner LO, Vejtorp M. Continuous use of oral contraceptives: an overview of effects and side-effects. Acta Obstet Gynecol Scand. 2013; 92(2): 125-136, doi: 10.1111/aogs.12036, indexed in Pubmed: 23083413. 
20. World Health Organization (2004) Contraception in adolescence. World Health Organization Library Cataloguing-in Publication Data, Geneva .

21. World Health Organization (2009) Medical eligibility criteria for contraceptive use. 4th Edition. World Health Organization Library Cataloguing-in-Publication Data, Geneva .

22. Quint EH, O'Brien RF. COMMITTEE ON ADOLESCENCE, North American Society for Pediatric and Adolescent Gynecology. Menstrual Management for Adolescents With Disabilities. Pediatrics. 2016; 138(1), doi: 10.1542/peds.2016-0295, indexed in Pubmed: 27325636.

23. Stewart FH, Kaunitz AM, Laguardia KD, et al. Extended use of transdermal norelgestromin/ethinyl estradiol: a randomized trial. Obstet Gynecol. 2005; 105(6): 1389-1396, doi: 10.1097/01.AOG.0000160430.61799.f6, indexed in Pubmed: 15932834.

24. Polskie Towarzystwo Ginekologiczne. Rekomendacje Polskiego Towarzystwa Ginekologicznego dotyczące wskazań i bezpieczeństwa stosowania antykoncepcji hormonalnej oraz wewnątrzmacicznej. Ginekol Pol. 2014; 85(3): 234-239.

25. French RS, Cowan FM. Contraception for adolescents. Best Pract Res Clin Obstet Gynaecol. 2009; 23(2): 233-247, doi: 10.1016/j.bpobgyn.2008.12.002, indexed in Pubmed: 19171502
26. Sulak PJ, Smith V, Coffee A, et al. Frequency and management of breakthrough bleeding with continuous use of the transvaginal contraceptive ring: a randomized controlled trial. Obstet Gynecol. 2008; 112(3): 563-571, doi: 10.1097/AOG.0b013e3181842071, indexed in Pubmed: 18757653.

27. Villavicencio J, Allen RH. Unscheduled bleeding and contraceptive choice: increasing satisfaction and continuation rates. Open Access J Contracept. 2016; 7: 43-52, doi: 10.2147/OAJC.S85565, indexed in Pubmed: 29386936

28. Jirakittidul P, Somyaprasert C, Angsuwathana S. Prevalence of Documented Excessive Weight Gain Among Adolescent Girls and Young Women Using Depot Medroxyprogesterone Acetate. J Clin Med Res. 2019; 11(5):326-331, doi: 10.14740/jocmr3792, indexed in Pubmed: 31019626.

29. World Health Organization. Technical Consultation on the Effects of Hormonal Contraception on Bone Health: Summary Report. Geneva, Switzerland: World Health Organization: 2005. http://whqlibdoc.who. int/hq/2007/WHO_RHR_07.08_eng.pdf (4.05.2015).

30. Pillai $\mathrm{M}, \mathrm{O}$ 'Brien $\mathrm{K}, \mathrm{Hill} \mathrm{E}$. The levonorgestrel intrauterine system (Mirena) for the treatment of menstrual problems in adolescents with medical disorders, or physical or learning disabilities. BJOG. 2009; 117(2): 216-221, doi: 10.1111/j.1471-0528.2009.02372.x. 